\title{
O PROCESSO DE CUIDAR NA ENFERMAGEM: MUDANÇASE TENDÊNCIAS NO MUNDO DO TRABALHO
}

[The caring process in nursing: changes and trends in the working world]

[El proceso del cuidar en enfermería: cambios y tendencias

en el mundo del trabajo]

\author{
Rita de Cássia Duarte Lima* \\ Elizabete R egina A . de Oliveira** \\ Nágela Valadão Cade*** \\ M ariana L aignier Rabello**** \\ Liliana Graça Santana*****
}

RESUMO: Trata de um texto reflexivo sobre o processo de trabal ho em saúde e os desafios da enfermagem diante das demandas contemporâneas. Propõe como ferramenta a mobilização das tecnologias leves subsidiando os processos relacionais, ou seja, o desenvolvimento de uma gestão do cuidado mediado pela comunicação, reciprocidade e afetos.

PALAVRAS-CHAVES: Processo de trabalho; Trabalho em saúde; Gestão de cuidado.

\section{IINTRODUÇÃO}

Este texto foi construído a partir de algumas experiências e reflexões coletivas que temos vivenciado como docentes, pesquisadoras e formadoras de trabal hadores de saúde para a área de Enfermagem/saúde. Nessa reflexão, tomamos como eixo norteador o processo de trabalho em saúde, situando a Enfermagem como uma prática social, que é construída cotidianamente, na relação com outras práticas e saberes, estando, assim, submetida às

\footnotetext{
*D outora em Saúde Coletiva; docente do Programa de Pós-Graduação em A tenção à Saúde Coletiva e do Curso de Graduação em Enfermagem da Universidade Federal do Espírito Santo.

**D outora em Enfermagem; docente do Programa de Pós-Graduação em A tenção à Saúde Coletiva e do Curso de Graduação em enfermagem da Universidade Federal do Espírito Santo.

***D outora em Enfermagem; docente do Programa de Pós-Graduação em A tenção à Saúde Coletiva e do Curso de Graduação em Enfermagem da Universidade Federal do Espírito Santo.

****M estre em A tenção à Saúde Coletiva pela U niversidade Federal do Espírito Santo; docente do Curso de Graduação em Enfermagem da Escola de M edicina da Santa Casa de M isericóridia.

*****M estre em A tenção à Saúde Coletiva pela U niversidade Federal do Espírito Santo; enfermeira do Centro de Referência em Saúde do Trabalhador do Espírito Santo.
}

mesmas lógicas e equívocos que vêm conformando 0 processo produtivo em diferentes áreas.

\section{REFLEXÕES SOBRE O PROCESSO DE CUIDAR NA ENFERMAGEM}

Quando, na academia, pensamos a respeito do tema mudança, precisamos reconhecer que as universidades têm sido muito lentas e os serviços têm sido mais eficientes e ágeis, em relação às instituições formadoras, em se adaptar e operar transformações, e na incorporação de tecnologias, entendidas aqui como equipamentos e mudança de atitudes dos profissionais.

Os setores de serviço e os setores de ensino têm vivenciado desafios semelhantes quanto às mudanças, principalmente no que diz respeito à necessidade de revisão dos model os gerenciais, diante das demandas que emergem a todo instante.

0 processo de mudança tem ocorrido com tanta rapidez e com demandas aparentemente tão diferenciadas que nos leva a pensar que, em tempos atuais, constantemente estamos com a sensação de que deixamos de ser contemporâneos de nós mesmos, estamos cada dia mais nos sentindo devassados e invadidos por não conseguirmos, em um espaço de tempo tão curto, acompanhar as inovações tecnológicas.

Nesse processo, existe em cada um de nós a consciência de que a economia e a sociedade são regidas por novos imperativos, por uma tecnociência computadorizada que invade não só o mundo do trabal ho, em especial, mas também o nosso espaço pessoal, tornandonos objetos, coisificados e sujeitados a tantas novas ordens.

A marca desse novo tempo tem sido dada pela relevância da máquina e da informação e o contato entre pessoas passa a ser mediado pela tela el etrônica. A ssim, 0 
mundo social se desmaterializa, transforma-se em signos, e a realidade torna-se virtual e transparente ${ }^{(1)}$.

Nesse sentido, estamos e temos sido construtores da sociedade do imediato, da falta de tempo para o lazer, para ser solidário, para importar-se com o outro e às vezes até consigo mesmo. A ilimitada evolução da ciência e da técnica não pára de nos surpreender e revolucionar o nosso cotidiano e a capacidade de produzir mais e melhor parece não ter fim. É clone, são células-tronco, ou seja, as necessidades e as novidades parecem infindáveis.

$M$ as existem inquietações e ruídos acerca dessa onipotência de que tanto a ciência quanto a técnica têm se revestido e começa-se a perceber que elas são, simultaneamente, hegemônicas e precárias, pois, apesar dos acontecimentos positivos, trazem, também, acontecimentos nefastos para a sociedade.

No mundo glamourizado da ciência, o poder, a produção e a mercadoria trazem consigo também 0 desemprego, a exclusão, a concentração de renda e 0 subdesenvolvimento, favorecendo o sentimento de impotência diante de tantos impasses, da instabilidade e da precariedade das conquistas. A s contradições que al imentam os movimentos de mudanças no capitalismo contemporâneo se amparam no binômio exclusão versus inclusão (1).

A incorporação de novas tecnologias, além de ser irreversível e de suma importância para nossa sociedade, traz também muitas contradições, dentre elas a premente necessidade da geração de produtos de consumo imediato, inclusive no que se refere ao nosso corpo, aos nossos empregos e trabalho e às formas de cuidar e prestar assistência à saúde das pessoas.

$R$ efletindo sobre esta crise que permeia a sociedade atual, D upas ${ }^{(1)}$ afirma que o homem tem se tornado perigoso para si mesmo, constituindo-se em seu próprio risco, inclusive pela gradual perda da capacidade de se auto cuidar e cuidar dos outros, em uma perspectiva solidária, humana e afetiva.

E ssa situação, certamente, repercute em todos, mas, em especial , afeta determi nadas profissões, cujo sentido para a sua existência está na relação com o outro, como o é, por exemplo, a profissão de Enfermagem. A o pensar no trabal ho em saúde, temos que reconhecer a sua singularidade de se produzir em ato e na rel ação com o outro. Falar em trabal ho é ao mesmo tempo vir à tona a produção e expansão da vida do jeito que ela é, no que tem de desejante, de afetos, de sofrimentos e de produção de sentidos. E esse constitui um dos paradoxos dessa sociedade, pois, ao mesmo tempo em que vamos perdendo muitas das dimensões humanas, vamos também produzindo maiores demandas para humanizar as relações e a vida em sociedade, buscando um agir pautado na ética e na solidariedade, inclusive nas relações de trabal ho que também são atravessadas por essas lógicas (2).

É fundamental buscar entender os processos de mudanças no contexto das lógicas que as formatam para não se perder de vista que as crises vividas como parte do nosso trabalho estão muito al ém do nosso desejo e do nosso autogoverno para sozinhos operar ou impedir as mudanças.

Nesse sentido, as crises decorrentes do mundo do trabal ho estão instituídas nos vários lugares institucionais, inclusive estão no interior da Enfermagem, sendo muito mais abrangentes que as crises de identidade profissional, que nossos desejos e vontades, daí a importância de entender o que se passa na sociedade, as tendências e expectativas sobre o papel social da Enfermagem para podermos intervir na realidade, como formadores e responsáveis pela organização cotidiana do trabalho nas instituições tanto formadoras, quanto de serviço.

N esse sentido, é fundamental entender o significado do que seja o trabal ho em saúde, como é realizado, em que condições, por quem e para que é produzido. 0 trabalho em saúde é produzido em sua maioria no âmbito institucional, seja no ambulatório, seja no hospital, seja em unidades de saúde, estando ainda muito atrelado à complexidade e à tecnologia hospitalar, mas tem crescido em outros espaços, como o domiciliar, empresas e outros.

0 trabalho em saúde se produz muito além das tecnologias entendidas como máquinas/equipamentos que são usados nas ações de intervenções realizadas sobre os usuários dos serviços. No trabal ho em saúde, qual quer que seja nossa abordagem com o usuário, haverá sempre rel ações mediatizadas por uma pessoa atuando sobre a outra, havendo, nesse processo de trocas, jogos de expectativas, momentos de fala, escutas e interpretações, nos quais existe a produção de vínculos, de uma acolhida ou não das intenções que essas pessoas colocam nesse encontro ${ }^{(2,3)}$.

Dessa forma, pensar processos de mudanças, em particular para esse setor, tem, necessariamente, que considerar, ao mesmo tempo, tanto a mudança das pessoas, dos seus valores, da sua cultura ou ideol ogia, dos seus estilos de gerenciar pessoas, quanto providenciar alterações no funcionamento das instituições de saúde ${ }^{(2,3)}$. As mudanças têm que ter impactos nos processos de trabalho de tal forma que o trabal hador se reconheça no seu trabal ho, na relação com o objeto e com seus instrumentos de trabalho.

As tendências mundiais sobre as perspectivas da utilidade ou não de determinados trabal hos têm apontado 0 crescimento e o papel insubstituível das denominadas profissões de ajuda, nas quais a Enfermagem comparece como uma das dez mais promissoras para os desafios que estão postos no século/milênio que se inicia (2).

E quais estratégias temos vislumbrado, como formadores de pessoal de Enfermagem? Quais são as estratégias que os gestores estão pensando para organizar o sistema e serviços tendo como um dos parceiros fundamentais o profissional de Enfermagem? E as entidades de classe da Enfermagem, o que têm a contribuir nesse debate?

Tanto na academia, quanto no serviço, temos produzido poucas alternativas, temos sido pouco ousados, 
ainda não nos demos conta da dimensão e significado dessa realidade. As poucas ações têm tido mais impacto na dimensão teórica, têm contaminado pouco o dia-a-dia, a formulação de políticas públicas e 0 próprio processo ensino-aprendizado, mas já é um começo.

As demandas que emergem para o profissional de Enfermagem têm apontado que esse trabalho não pode ser uma simples reprodução de técnicas, fragmentado, impessoal e destituído de afeto, felicidade, alegria e solidariedade. Ele tem que produzir víncul os entre os vários protagonistas-usuários, trabalhadores e instituições - ou seja, ele precisa ser produtor de um tipo de acolhimento que potencialize as pessoas, os processos de trabalho, contribuindo para mudanças na concepção da saúde e cuidado em saúde como um direito, inclusive do trabal hador.

A necessidade de profissionais de ajuda toma como eixo a premente carência do indivíduo em ser cuidado, ser acol hido em determinado momento de suas vidas, em que o fragilizar é a própria situação do estar doente, envelhecido ou abandonado/individual izado pel as crenças geradas pelo mundo globalizado e mediadizado pelo consumo e pelo ter.

Em nossa compreensão, o processo de mudança independe do nosso ritmo, das nossas diferenças e divergências políticas e até mesmo das nossas concepções de mundo. Ele aponta tendências e expectativas em relação à produção de um modo de fazer Enfermagem baseado na evidência da solidariedade, da comunicação, ou seja, da competência humana que étambém ética e técnico-política.

A respeito do processo de trabal ho da Enfermagem, é preciso entender que el e se realiza como um trabal ho que se constitui no interior do trabalho em saúde, produzindose na sua relação com os outros trabalhos de saúde e na sociedade capitalista e, nessa articulação, reconhecemos a complementaridade deste trabal ho com outros e não a sua sujeição a outros trabal hos (4).

Posto isso, a discussão remete-nos a seguinte interrogação: quais são, concretamente, as possibilidades dadas pel o trabalho da Enfermagem, para constituir-se num dos protagonistas de mudanças nas lógicas que vêm moldando as transformações no mundo do trabal ho?

Temos apostado nas nossas possibilidades como protagonistas, naquilo que temos de maior governabilidade para intervir, que éo nosso objeto de trabal ho, o ser humano, necessitando de cuidados solidários e comprometidos com a vida humana. $\mathrm{A}$ isso temos chamado de incorporação da tecnologia do cuidado, do saber e do fazer cotidiano.

$\mathrm{N}$ a realidade, estamos buscando (re) significar não só o discurso, mas as nossas distintas práticas cotidianas. Estamos falando e propondo um cuidar que não é apenas assi stir e tratar das pessoas numa perspectiva apenas técnica, não é, simplesmente, cuidar enquanto a ação de fazer 0 curativo, dar medicação, prestar cuidados diretos e administrativos; é, antes de tudo, um processo de cuidar (des) vinculado do sofrimento, do sentimento de compaixão pelo outro, pois a compaixão apaga as diferenças, elimina o espaço material que separa os homens entre si, aproxima as pessoas não pela palavra, mas sim pelos gestos ou pelos silêncios ${ }^{(5)}$. Segundo B off ${ }^{(5: 126)}$, a com-paixão não deve ser um sentimento menor de "piedade com o sofrimento do outro. A com-paixão éa capacidade de compartilhar a paixão do outro, com o outro".

0 vínculo que se produz no cuidar solidário é criado na relação entre iguais humanos que reconhecem necessidades desiguais, tais como as desigualdades no acesso aos serviços de saúde e na integralidade do cuidado. Precisamos resgatar uma forma de cuidar, cuja mediação se faça pelo contato, pela comunicação, pelo afeto, pela possibilidade de reconhecer-se e colocar-se no lugar do outro e também pelo respeito às diferenças de conhecimento de práticas e nos modos de ver e viver a vida, permitindo, assim, a possibilidade de, no encontro, conhecer 0 que 0 outro pensa, deseja e do que diverge.

0 cuidar solidário exige reciprocidade, 0 reconhecimento do outro como um igual em orgulho, em sentimento, afeto e dignidade. A utores ${ }^{(3,5,6,6)}$ têm nos mostrado que 0 ato de cuidar exige responsabilidade, sentimento, envolvimento e comprometimento pessoal, afetivo, social, moral e espiritual.

Se olharmos com atenção para os processos de trabal ho que se produzem cotidianamente nas instituições/ serviços, veremos, segundo M erhy ${ }^{(3)}$, que 0

[...] conjunto das intervenções assistenciais, além das várias ferramentas máquinas que usamos como raio $X$, instrumentos para examinar os pacientes, etc, mobilizamos intensamente conhecimentos, sobre as formas de saberes profissionais, bem estruturados, como por exemplo o saber da enfermagem" (p.122).

0 ato de cuidar deve constituir a alma dos serviços de saúde e, para tal, M erhy ${ }^{(3)}$ nos apresenta "caixas de ferramentas" constituídas a partir de um modo de produzir tecnologias que denomina de leves, leves-duras e duras.

A o repensarmos o processo de formação dos profissionais de Enfermagem, mobilizamos, além das tecnologias duras (equipamentos, procedimentos etécnicas) e as leves, produzidas a partir dos processos relacionais, as leves duras (conhecimentos), e isso nos remete à real idade das nossas condições de trabal ho/ensino, que tem mostrado o quanto tomar o cuidado como estratégia nos ajuda também como possibilidade para intervir nos processos de trabal ho e nele operar mudanças, por exemplo, nos estil os gerenciais que produzem o trabal ho da Enfermagem denominados por Lima ${ }^{(2)}$ como conservadores, controladores, adoecedores e autoritários ${ }^{(1)}$.

A (re) significação do nosso trabalho a partir de uma outra maneira de produzir a tecnologia do cuidado, conforme estamos propondo, se estrutura em nós mesmos ou, como afirma B off ${ }^{(5)}$

[...] não temos cuidados, somos cuidados, uma vez que o cuidado possui uma dimensão ontológica, que entra na consti-

Cogitare Enferm 2005 mai/ago; 10(2):63-67 
tuição do ser humano. É um modo de ser singular do homem e da mulher. Sem cuidado deixamos de ser humanos (p. ${ }^{(9)}$.

A ssim sendo, a tecnologia do cuidado se produz quando a existência das pessoas torna-se significativa, independente do papel que estejamos ocupando (enfermeira, docente, equipe, usuário). 0 sentimento de importância é que nos leva a dedicarmos ao outro, a participar do seu destino, de suas buscas, dos seus sofrimentos, dos seus afetos, dos seus sucessos, avanços e mesmo dos seus fracassos e limites.

0 ato de cuidar a ser ensinado aos futuros profissionais precisa incluir valores, desejos e compromissos com o cuidado e com o conhecimento. 0 ato de cuidar do outro requer dimensões amplas e abrangentes que contemplem, na prática, questões humanísticas, sociais, éticas, culturais, biológicas e espirituais, determinando, no processo de ajuda mútua e do saber/fazer interdisci plinar, o crescimento e o envolvimento entre 0 cuidador e 0 ser a ser cuidado, tornando-se favorecedor do autocuidado e da autonomia do sujeito cuidado/cuidador.

0 resgate do cuidado a ser apreendido não se faz à custa do descuidado, do trabal ho rotineiro, tarefeiro, destituído de prazer, de criatividade e da subjetividade; no contrário, ele se faz, principalmente, mediante uma forma diferente, prazerosa, ousada e criativa de entender e de realizar o trabalho.

Para isso, o ser humano, aqui representado pelo trabal hador deE nfermagem, precisa voltar-se para si mesmo e (re) descobrir seu modo de cuidar, ser cuidado e de se cuidar, credenciando-se a cuidar de outras pessoas. Pessoas adoecidas, infelizes, não criam vínculos positivos e precisam ser acolhidas, cuidadas.

0 cuidador que vislumbramos para fazer frente às novas demandas do mundo do trabal ho toma como fundante a forma de prestar cuidados centrada no ser humano demandante de necessidades, tomando a defesa da vida como um dos compromissos inerentes à sua identidade como sujeito no mundo, portador de conhecimentos e práticas que o credencia a ser produtor do trabalho em saúde e na Enfermagem.

É nesse sentido que vislumbramos como possibilidade a tecnologia do cuidado, também como uma potente ferramenta para recompor e rel ativisar os processos de mudanças na e para a Enfermagem, na formação e nos serviços de saúde e para atender às demandas por cuidados prestados por esses profissionais.

Portanto, tomar como ponto de reflexão a provocação da escala, um dos mais potentes instrumentos de trabalho, pela demonstração de poder e da autonomia da enfermei ra, por esse procedimento, por ser controlador, autoritário, revelador da insatisfação dos trabal hadores de nível médio, em particular, nos pareceu singular para demarcar essas fronteiras que têm produzido o nosso trabal ho cotidiano.

Gostaríamos de reafirmar a nossa crença de que o ato de produzir tecnol ogia para o cuidar se ef etiva, também, num processo comunicativo, em que a ação de cuidar envolve a relação do sujeito que cuida, consigo mesmo e com o sujeito a ser cuidado, ou seja, se inicia nas formas como cuidamos em primeiro lugar de nós mesmos, do nosso corpo, espírito e sentimentos, isto é, se corporifica nas formas que escol hemos por fazer a gestão da vida na relação com as pessoas.

\section{CONSIDERAÇÕES FINAIS}

Finalizando, acreditamos que tudo começa com 0 sentimento e, como nos diz B off ${ }^{(5)}$, é o sentimento que nos faz sensíveis ao que está à nossa volta, que nos faz gostar ou desgostar, acolher ou rejeitar, estar ou não implicado com a vida, a felicidade, a saúde e o nosso trabalho. É 0 sentimento que nos une/desune às coisas e nos envolve com as pessoas e, nesse processo com a nossa humanidade, é 0 sentimento que produz ou não solidariedade, vínculo, aconchego e encantamento. É o sentimento que torna coisas, situações e pessoas importantes e significativas para o outro e para si mesmo. Como afirma o autor, é esse sentimento que deve ser produtor do cuidado, inclusive no trabal ho em saúde/Enfermagem.

ABSTRACT: It is a thought-provoking text about the working process in heal th and the nursing challenges facing contemporary demands. It proposes as a tool the mobilization of light technologies subsidizing the relational processes, that is to say, the development of a care management mediated by communication, reciprocity and affection.

KEYWORDS: Working process; Work in health; Care management.

RESUMEN: Este es un texto reflexivo acerca del proceso de trabajo en sal ud y los desafíos de la enfermería ante a las demandas contemporáneas. Propone como herramienta la movilización de las tecnologías ligeras, subsidiando los procesos de relación, es decir, el desarrollo de una gestión del cuidado mediado por la comunicación, la reciprocidad y el sentimiento.

PALAVRAS-CLAVE: Proceso de Trabajo; Trabajo en Salud; Gestión del Cuidado.

\section{REFERÊNCIAS}

1. Dupas G. Ética e poder na sociedade da informação. São Paulo: U nesp; 2000.

2. Lima RCD. Enfermeira, uma protagonista que produz o cuidado no cotidiano do trabalho em saúde. Vitória:Edufes; 2001. 
3. M erhy EE. Saúde a cartografia do trabalho vivo. São Paulo: Hucitec; 2002.

4. A Imeida M CP, Rocha SM M, organizadores. 0 trabal ho de enfermagem. São Paulo: Cortez; 1997.

5. B off L. Saber cuidar ética do humano compaixão pela terra. Rio de Janeiro: Vozes; 1999.

6. Oliveira $M E$, Scavone $L$, organizadores. Trabalho, saúde e gênero na era da globalização. Goiânia: A B; 1997.

7. Waldow RR, Lopes M JM, M eywe DE. M aneiras de cuidar maneiras de ensinar: a enfermagem entre a escola e a prática profissional. Porto A legre: A rtes M édicas; 1995.

\author{
ENDEREÇO DOSAUTORES: \\ R. A fonso Celso, 694/152 B \\ São Paulo-SP \\ 04119-060 \\ nagelavc@terra.com.br
}

